\title{
Instrumental and Affective Aspects of Physician Behavior
}

\author{
JOZIEN M. BENSING, PHD, AND JOHAN DRONKERS
}

\begin{abstract}
In a semi-replication study, 103 videotaped real-life general practice consultations of patients with hypertension were observed with Roter's interaction Analysis System (RIAS). RIAS consists of a detailed category system meant to measure each verbal utterance of physician and patient (distinguished in taskrelated behavior and socio-emotional behavior) and a set of global affect-ratings. In this article, only general practitioner (GP) behavior is studied. GP's behavior is related to panel-assessed quality of care on three separate dimensions (technical-medical, psychosocial, and the management of the physicianpatient relationship). A remarkably high percentage of the variance in the quality assessments (ranging from $59 \%$ to $70 \%$ ) was explained by RIAS. The global affect-ratings proved to have the strongest influence in all quality assessments. In addition, task-related behavior seems to be more important in medical technical behavior, whereas socio-emotional behavior, and especially the psychotherapeutic categories like reflecting, paraphrasing, showing agreement, and others, seem to be more important in the other quality measures. The results are compared with Roter's study; similarities and differences are discussed in light of adjustments in the methodology. A plea is made for cross-cultural comparisons in physician behavior. Key words: observation study; video; hypertension; doctor-patient communication; affective behavior; instrumental behavior; cross-cultural comparison. (Med Care 1992; 30:283-298)
\end{abstract}

In medical communication two types of behavior are thought to be important: instrumental behavior and affective behavior. ${ }^{1-11}$ They correspond with the two main purposes the doctor has in the medical consultation: information exchange, which is necessary for solving the medical problem; ${ }^{7,12-22}$ and creating a therapeutic relationship, which is necessary for managing the psychosocial aspects of patient's health problems and gaining patient's confidence. $^{2,3,5,23-31}$ The reason that these two

From the Netherlands Institute for Primary Health Care, Utrecht, The Netherlands.

The study on which this article is based is part of the first author's thesis.

Address correspondence to: Mrs. Jozien M. Bensing, Netherlands Institute for Primary Health Care (NIVEL), P.O. Box 1568, 3500 BN Utrecht, The Netherlands. types of behavior are both so important in medical practice is that patients, when seeing a doctor, have two different types of needs that have to be met. ${ }^{32-34}$ As Engel ${ }^{32}$ stated, these are "the need to know and understand" (to know what is the matter with him or her, what causes the pain, and how this can be stilled) and the "the need to feel known and understood" (to know that he or she is accepted by the doctor as a person and is not seen as a malingerer). While most people agree about the relevance of both types of behavior, there is considerable debate about the relative importance of both. ${ }^{34} \mathrm{Re}$ searchers from a psychotherapeutic background (with Rogers ${ }^{35}$ and Balint ${ }^{23}$ as leading theorists) claim the predominance of affective behavior, $2,5,36$ while others (mostly inspired by Bales' observation system, which is based on problem solving theories ${ }^{37}$ ), claim that instrumental behavior is 
the most important part of physician's behavior. ${ }^{7,8,38}$

To gain more insight into the contradictory results found in the literature, a study was designed in which both instrumental and affective physician's behavior was observed and subsequently related to panelassessed quality of care. The purpose of our study is to explore the internal relationships between instrumental and affective behavior (verbal as well as nonverbal) and to compare the strength of process-outcome associations across these main groups. Roter's Interaction Analysis System (RIAS) is chosen to measure instrumental and affective behavior because this system was used before in a study into the relative contribution of affective and instrumental behavior to the quality of care ("medical proficiency"). ${ }^{7}$ In this way, a comparison of the results of both studies is possible. RIAS is regarded as a suitable observation system for our research purpose because it originates in the problem-solving tradition, with its focus on instrumental behavior, but is adapted later on (partly after the study just mentioned) to measure affective behavior as well. Moreover, Roter's system is well documented ${ }^{39}$ widely used, ${ }^{7,8,19,40-45}$ and judged relatively favorably in a comparison study. ${ }^{43}$

\section{Methods}

\section{Sample}

For this study videotaped consultations were used from a larger research project, entitled "Interpretation and Treatment of Psychosocial Problems," that was published as a thesis ${ }^{46}$ (see also ${ }^{30,47}$ ). The 30 doctors who participated in this project were all general practitioners (GP); they were all white and, with one exception, male. Their average age was somewhat lower than the average age of the Dutch population of general practitioners. They had followed more postgraduate courses in psychosocial care but did not differ from a representative sample of general practitioners in task perception, per- ceived competence, or multidisciplinary cooperation. Details about the selection and composition of the sample of general practitioners can be found in Verhaak's thesis. ${ }^{30}$

In each of their practices video-recordings were made on 3 or 4 consecutive days for all consecutive patients. This resulted in 1,569 videotaped consultations. For our study, a further selection was made from that particular random selection. This was done to prevent heterogeneity, an often underestimated problem in research in doctor-patient communication. ${ }^{44}$ It was possible to select consultations with a common health problem because the GP's that took part in the larger project noted, in addition to other things, all health problems that arose in the consultation. Trained coders coded the health problems in terms of the International Classification of Primary Care (ICPC). Our sample consists of all 103 consultations of patients with hypertension (K85 to K87), selected from the total sample of videotaped consultations for that reason only. The rationale behind the choice for patients with hypertension or other blood pressure problems was the need for a homogeneous sample, with a health problem that is considered serious enough to deserve devoted medical attention, and that seems to require a biopsychosocial approach. The latter is thought to be important because, in general practice, health problems seldom seem to require a somatic solution alone. ${ }^{31}$

The amount of 103 consultations of patients with hypertension out of a random sample of $1,569(=6.6 \%)$ is in keeping with expectations of the morbidity-distribution in a random sample of consultations in general practice. ${ }^{48}$ The age-sex distribution of the patients is shown in Table 1 and is similar to distributions found in morbidity research in general practice. $^{49}$

The patients are all Dutch-speaking and predominantly white. The majority of the consultations $(76 \%)$ involve a repeat visit. This is also to be expected because hypertension is a chronic complaint. By way of 
TABle 1. Age-Sex Distribution of Patients with Hypertension

\begin{tabular}{lccccc}
\hline Age (yrs) & Man & Woman & Total & $\begin{array}{c}\text { Total } \\
\text { NS }^{a}\end{array}$ & $\begin{array}{c}\text { Total } \\
\text { NMS }^{b}\end{array}$ \\
\hline$<45$ & 11 & 10 & $21(20 \%)$ & $(14 \%)$ & $(10 \%)$ \\
$45-64$ & 10 & 23 & $33(42 \%)$ & $(44 \%)$ & $(47 \%)$ \\
$65-74$ & 11 & 14 & $25(24 \%)$ & $(27 \%)$ & $(29 \%)$ \\
$\geq 75$ & 3 & 11 & $14(14 \%)$ & $(14 \%)$ & $(14 \%)$ \\
Total & 35 & 68 & $103(100 \%)$ & $(100 \%)$ & $(100 \%)$ \\
Total & $(34 \%)$ & $(66 \%)$ & $(100 \%)$ & & \\
Total NS & $(37 \%)$ & $(63 \%)$ & $(100 \%)$ & & \\
Total NMS & $(35 \%)$ & $(65 \%)$ & $(100 \%)$ & & \\
\hline
\end{tabular}

NS, Dutch National Study of Morbidity and Interventions in General Practice.

NMS, Second National Morbidity Survey (U.K.).

" Source: Nationale Studie van Ziekten en Verrichtingen in de Huisartspraktijk, NIVEL, unpublished manuscript.

${ }^{b}$ Source: Office of Population Censuses. ${ }^{49}$

comparison, in the British Second National Morbidity Survey, $63 \%$ of the hypertension consultations were repeat consultations; ${ }^{49}$ in the Rotterdam Monitoring project, $59 \%$ of the consultations for high blood pressure, and even $95 \%$ of the consultations for essential hypertension were repeat consultations. ${ }^{50}$ As is shown in other studies, ${ }^{51}$ comorbidity plays an important role in general practice. In the greater part of the consultations $(61 \%)$, other health problems were also involved in addition to the hypertension problem. In this respect, the selected consultations do not deviate from the average consultation of a patient with hypertension. We may, on the basis of this data, conclude that the selected videotaped consultations provide an adequate reflection of hypertension consultations as these arise in general practice, and, as such, they form suitable research material for this study.

\section{Dependent Variables: Quality of Care}

In terms of Donabedian's useful distinction (structure-process-outcome) ${ }^{52}$ the focus in this study is on the process of care. Quality of care was measured by a panel of 12 experienced GP's using a threefold assessment of: 1) quality of GP's technicalmedical behavior, 2) quality of GP's psychosocial behavior, and 3) quality of GP's management of the doctor-patient relationship.
The GP's, who made their assessments independently of one another, rated the GP's performance (as in the Dutch school grading system) on three 10-point scales. They were asked to make global assessments weighing up for themselves the different elements that are thought to be important in each type of behavior. These were summarized in a paper they had to complete during the assessments. For instance, the panel-members were provided with an overview of the major elements of the Nÿinegen University Institute of General Practice Hypertension Protocol as a guide in assessing the technical-medical quality. In addition, they were asked to pay attention to some general aspects of quality of care in general practice, such as the avoidance of superfluous treatment and a correct designation of patients as ill or healthy. In the assessment of psychosocial care the panel-members were asked to pay attention to, among other things, the degree to which the GP was receptive to the nonsomatic aspects relating to the complaint and to his or her actual treatment; these were not only to involve psychosocial problems as such but also stress-related factors in the origin of the hypertension and the problems caused by it and by its treatment. Concern in the quality of the doctor-patient relationship was exclusively with the manner in which the GP dealt with the patient, in particular the degree in which he or she was 
successful in creating an open, secure, and workable relationship with the patient. These global assessments proved to be reliable with Cronbach's alphas of $.79, .88$, and .88 , respectively. Moreover, the scores showed a wide range; the panel-members were not afraid to give low scores as well as high scores. An analysis of variance (ANOVA) did reveal differences in the three measures of quality among the consultations but not among the panel-members. The 12 panel-members' scores were averaged to get a single measure for the quality of care for each of the three distinguished dimensions. ${ }^{53}$

To get an integrated assessment of the quality of care, the panel-members were also asked to rate GP behavior on seven 5point scales, representing different dimensions of a "generalistic orientation," as opposed to a biomedical approach, which is thought adequate for general practice (see Appendix). In a former study, ${ }^{53}$ this scale also proved to be reliable with interassessoralphas of between .77 and .93 and an interitem alpha (using the summated score for each item) of .93. A factor-analysis on this summated scale showed one clear factor that explained $70.9 \%$ of the variance. The scale's sumscore is used in the analyses.

\section{Independent Variables: Doctor-Patient Communication}

Doctor-patient communication was measured by Roter's Interaction Analysis System (RIAS), i.e., Roter's modification of Bales' process analysis scheme. ${ }^{37}$ The unit of analysis for this scheme is a verbal utterance, defined as the smallest discriminable speech segment to which a coder can assign a classification. This may be a single word, a clause, or a complete sentence. All utterances are assigned to mutually exclusive categories. The system is described in detail in several publications, ${ }^{7,8,19,39-42}$ sometimes with minor adjustments. The latest version ${ }^{39}$ is used in this study. To avoid interpretation problems, neither the behavioral categories nor the manual with full instructions were translated, but instead the original documents were used. The application of the observation system was facilitated by the availability of six audiotaped American consultations and their complete transcripts in which the correct codes were noted. These were used for training purposes.

After training, all 103 consultations were coded by one observer. Twenty-five of these were also coded by a second observer to test the reliability of the observations. The reliability of the observations proved to be high, with inter-observer correlations (Pearson's Product Moment Correlation) between .76 and .99 for the GP's categories and between .67 and .99 for the patient's categories.

Our version of RIAS consists of 35 behavioral categories. All categories were filled in for GP and patient, separately. In this article only GP's behaviors have been analyzed. The amount of categories made it necessary to reduce these into meaningful clusters within the two main groups of the system: 1) task-related or instrumental behavior and 2) socio-emotional or affective behavior.

Instrumental Behavior (RIAS). The following task clusters were formed by Roter: ${ }^{7,8}$

1) Information: all information statements related to medical condition, therapeutic regimen, lifestyle, feelings, other;

2) Questions: all open-ended and closedended questions as well as asking for understanding, clarification, or opinion;

3) Counseling: all persuasive statements related to medical condition, therapeutic regimen, lifestyle, and feelings;

4) Directions: all statements that guide the patient through the consultation (for example, "Sit down, I'll have a look first", and others.).

These task clusters are used in the analyses. Additionally, the first three clusters have been split up in "medical" and "psychosocial" (combining "feelings" and "lifestyle"). This was done because of our interest in the biopsychosocial aspects of the GP's health care, as is also reflected in the 
threefold quality rating (mentioned previously).

Affective Behavior (RIAS). Roter's affective cluster consisted of four variables (personal remarks, jokes, approvals, and agreements) "which were averaged to form a positive socio-emotional cluster." ${ }^{17}$ (p. 406) Because of Roter's low correlations between this socio-emotional cluster and medical proficiency, ${ }^{7,8}$ which is contrary to results from other studies, special attention has been paid to the content of the socio-emotional part of Roter's Interactional Analysis System. A factor analysis (Principal Components Analysis with varimax rotation) on the positive socio-emotional items produced three factors, explaining $55 \%$ of the variance: 1) verbal attentiveness: showing agreement, paraphrasing and reflecting patients' messages, legitimizing his or her behavior or feelings, and showing partnership; 2 ) showing concern: showing worry, and giving reassurance; 3 ) social behavior: personal remarks, jokes, showing approval.*

The categories loading high on one of the factors have been summated to form three positive socio-emotional or affective clusters. In addition, one negative affective behavioral category is included in the analyses, consisting of GP's statements of disagreement. This was done on an a priori base because of the different meaning of negative affective behavior as compared to positive affective behavior.

\section{Nonverbal Affective Behavior (Global} Affect Ratings) In addition to Roter's Interaction Analysis System, five global affect-scales were rated for GP and patient, separately. The same 6-point scales were used by Roter, ${ }^{19}$ although not in the publications about the relative relevance of instru-

* This "social factor" has a very high loading for "personal statements" and moderate loadings for "jokes" and "approvals"; the latter two items also have a (lower) loading on the other factors. Yet, for reasons of comparability with Hall and Roter's study, this factor is used in the analyses because, in its present form, the factor is much like Roter's socio-emotional factor? mental and affective behavior. The affectscales were meant to assess the following types of affect: ${ }^{39} 1$ ) anger/irritation; 2 ) anxiety/nervousness; 3) dominance/assertiveness; 4) interest/concern; and 5) warmth/ friendliness.

As can be expected from rating scales, ${ }^{7,8,29}$, $43,46,54,55$ the reliability of the global affect scales was a bit lower than the reliability of the counted items, but apart from the assessment of GP's dominance (Pearsons Product Moment Correlation: $r=.47)$, the figures are acceptable (ranging from .73 to .91). Dominance is excluded from the analyses.

\section{Data Analysis}

The principal efforts in data analysis were: 1) to explore the internal relationships between the three main groups of the observation system (task-related behavior, verbal socio-emotional behavior, together forming Roter's Interaction Analysis System) and the global affect ratings and 2) to compare the relative strength of process-outcomes associations across these main groups. Pearson's Product-Moment Correlations were computed for both research questions. Additionally, a series of stepwise multiple regressions were performed for the last research question, which treated the distinct measures of doctor-patient communication as independent variables and encounter outcome (several measures of panel-assessed quality of care) as dependent variables. For reasons described by Inui, ${ }^{43}$ the "explanatory power" of a given dependent variable is reported as the Adjusted $R^{2}$, which is a conservative estimate of total $R^{2}$. It gives the maximum amount of explained variance when the total explained variance is adjusted for the number of independent variables entering. Actual values for independent variables in all analyses were frequencies (counts) because treating independent variables as proportions did not substantively alter results in other studies, ${ }^{43}$ a result also found in our previous research. ${ }^{46}$ 
TABLE 2. Relationships (Pearsons' $R$ ) Between Task-Related Behaviors and Socio-Emotional Behaviors $(n=103)$

\begin{tabular}{lcccc}
\hline & Verbal Attentiveness & Showing Concern & Social Behavior & Disagreements \\
\hline Information & $.47^{b}$ & $.40^{b}$ & -.02 & $.44^{b}$ \\
Medical & $.53^{b}$ & $.35^{b}$ & -.01 & $.46^{b}$ \\
Psychosocial & .02 & .07 & -.18 & .19 \\
Questions & $.48^{b}$ & .06 & .11 & $.24^{a}$ \\
Medical & .21 & .06 & .13 & .21 \\
Psychosocial & $.32^{b}$ & -.03 & .01 & .02 \\
Counseling & $.52^{b}$ & -.01 & .12 & $.51^{b}$ \\
Medical & $.41^{b}$ & .08 & .11 & $.52^{b}$ \\
Psychosocial & $.33^{b}$ & -.11 & .07 & .18 \\
Directions & $.48^{b}$ & $.26^{a}$ & -.04 & $.26^{a}$ \\
\hline
\end{tabular}

${ }^{a} P<.01$.

${ }^{b} P<.001$.

\section{Results}

\section{Relations Among GP's Task and Socio-emotional Behaviors}

In Table 2 the correlations are shown between the task clusters and the socio-emotional clusters of Roter's Interaction Analysis System.

The factor "verbal attention" is strongly correlated with all four task clusters. However, when the topic of the conversation is taken intc account, some refinements of the overall picture can be shown. Doctors who show their attentiveness by paraphrasing the patient, reflecting or legitimizing his or her feelings and showing agreement or partnership, are also likely to give more medical information but not more psychosocial information; and they tend to ask more psychosocial questions but not more medical questions. They also do more counseling, regardless of the topic. Showing concern by reassuring the patient or showing worry is correlated with giving information (especially medical information) and directions, only. "Social behavior" (the cluster that was much like Roter's socio-emotional cluster) has no significant relationship with any of the four task clusters, not even when the topic of the conversation (medical or psychosocial) is taken into account. Strikingly, the negative socio-emotional category "showing disagreement" has a positive rela- tionship with all task clusters, especially with counseling and giving information. This is largely restricted, however, to conversation on medical topics.

\section{Relationships Between RIAS' Task and Socio-emotional Clusters and the Global Affect-Ratings}

In Table 3 the correlations are presented between the RIAS-cluster on the one hand, and the global affect ratings on the other.

General practitioners who show their irritation ask few questions during the consultation (especially few psychosocial questions). These GP's are also not very attentive in their verbal behavior and show no inclination to socialize with the patient. On the contrary, in these consultations there are many disagreements between GP and patient. Together, these results point to a malfunctioning relationship between the doctor and his or her patient. The same (but in a somewhat lesser degree) can be said of consultations in which the GP looks anxious or nervous. The mirror-image is formed by the general practitioner who shows interest in the patient and exudes warmth. These doctors are verbally attentive, display much social behavior, and ask many questions, especially psychosocial questions. Additionally, an interested doctor who radiates warmth seems to be active in all four task clusters; he or she also gives a lot of information (espe- 
TABLE 3. Relationships Between Rias' Task and Socio-Emotional Clusters and the Global Affect Ratings (Pearsons' Product Moment Correlation; $\mathrm{n}=103$ )

\begin{tabular}{lcccc}
\hline \multicolumn{1}{c}{ Task cluster } & Anger & Anxiety & Interest & Warmth \\
\hline Information & .06 & -.02 & $.23^{a}$ & $.22^{a}$ \\
Medical & .06 & .02 & $.19^{a}$ & $.21^{a}$ \\
Psychosocial & $.28^{b}$ & -.04 & -.03 & -.08 \\
Questions & $.17^{a}$ & $-.18^{a}$ & $.32^{c}$ & .11 \\
Medical & -.21 & $-.27^{c}$ & .16 & $.37^{a}$ \\
Psychosocial & -.04 & -.10 & $.34^{c}$ & $.20^{a}$ \\
Counseling & .05 & -.06 & .13 & .12 \\
Medical & -.11 & -.09 & $.17^{a}$ & $.17^{a}$ \\
Psychosocial & -.11 & -.01 & $.30^{b}$ & $.26^{b}$ \\
Directions & & & $.33^{c}$ & $.36^{c}$ \\
Socio-emotional cluster & $-.26^{b}$ & $-.23^{a}$ & .16 & .15 \\
Verbal attentiveness & -.11 & -.13 & $.26^{b}$ & $.32^{c}$ \\
Involvement & $-.23^{b}$ & $.35^{c}$ & -.03 & -.07 \\
Social behavior & $.31^{c}$ & & & \\
Disagreements & & & & \\
\hline
\end{tabular}

${ }^{a} P<.05$.

${ }^{b} P<.01$.

${ }^{c} P<.001$.

cially medical information) and does a lot of counseling (especially psychosocial counseling). However, no relationship with the doctor's disagreements has been found.

\section{Relations Between GP's Behavior and the Quality of Care}

In Table 4 the correlations are given between the observed behavior and panel-assessed quality of care; they are separated into medical-technical care, psychosocial care, and the management of the GP-patient relationship. The degree to which the GP displays a "generalistic orientation" (as opposed to a biomedical orientation) is the fourth measure in these analyses.

The original four task clusters (giving information, asking questions, counseling, and giving directions) all show positive correlations with each of the three quality measures. However, when split up into a medical and a psychosocial component, some differentiation arises: medical information seems to be important for all quality ratings, no matter the domain of care. However, psychosocial information has no significant relation with any of the three quality- ratings, not even with the quality-rating for psychosocial care. Counseling and questioning do show the expected relationships: medical counseling and questioning correlate with the quality rating for technical-medical care and not with the other two quality ratings; psychosocial counseling and questioning correlate with both the quality of psychosocial care and the quality of the GP-patient relationship but not with the quality of medical care.

When the GP displays a "generalistic" orientation during the consultation, as opposed to a biomedical orientation, he or she seems to display many activities, especially in the psychosocial area.

Of the socio-emotional clusters, verbal attentiveness has the strongest relationships with all quality-ratings, as well as with the $\mathrm{GP}^{\prime}$ generalistic orientation. A GP who shows concern about his or her patient's health problems by showing worry or giving reassurance is positively evaluated, too, but in a more moderate way. Social behavior (the category that is most like Roter's socioemotional cluster) only counts for the quality-rating on the way the GP manages the doctor-patient relationship. 
TABle 4. Relationship Between General Practitioner's Task and Socio-Emotional Behavior and Affect Ratings and the Quality of Care (Pearsons' $R ; \mathrm{n}=103$ )

\begin{tabular}{|c|c|c|c|c|}
\hline & $\begin{array}{l}\text { Quality of care } \\
\text { Medical }\end{array}$ & Psychosocial & Relationship & $\begin{array}{l}\text { Generalistic } \\
\text { Orientation }\end{array}$ \\
\hline \multicolumn{5}{|l|}{ Task behavior } \\
\hline \multicolumn{5}{|l|}{ Giving Information } \\
\hline Total & $.35^{b}$ & $.33^{b}$ & $.25^{b}$ & $.25^{a}$ \\
\hline Medical & $.41^{b}$ & $.32^{b}$ & $.30^{b}$ & .22 \\
\hline Psychosocial & .02 & .14 & .02 & .20 \\
\hline \multicolumn{5}{|l|}{ Counseling } \\
\hline Total & .22 & $.26^{a}$ & .18 & $.27^{a}$ \\
\hline Medical & $.23^{a}$ & .10 & .06 & .06 \\
\hline Psychosocial & .07 & $.28^{a}$ & .20 & $.34^{a}$ \\
\hline \multicolumn{5}{|l|}{ Questioning } \\
\hline Total & .22 & $.29^{a}$ & .20 & $.24^{a}$ \\
\hline Medical & .21 & .05 & .03 & .01 \\
\hline Psychosocial & .06 & $.34^{b}$ & $.24^{a}$ & $34^{b}$ \\
\hline \multicolumn{5}{|l|}{ Directions } \\
\hline Total & $.46^{b}$ & $.29^{a}$ & .22 & .14 \\
\hline \multicolumn{5}{|l|}{ Socio-emotional behavior } \\
\hline Verbal attentiveness & $.38^{b}$ & $.53^{b}$ & $.42^{b}$ & $.55^{b}$ \\
\hline Showing concern & $.25^{a}$ & .22 & $.25^{a}$ & .17 \\
\hline Social behavior & .14 & .16 & $.31^{b}$ & .23 \\
\hline Disagreements & .20 & .15 & .01 & .16 \\
\hline \multicolumn{5}{|l|}{ Affect ratings } \\
\hline Anger & $-.26^{a}$ & $-.45^{b}$ & $-.46^{b}$ & $-.41^{b}$ \\
\hline Anxiety & -.22 & -.27 & $-.30^{b}$ & $.65^{b}$ \\
\hline Interest & $.69^{b}$ & $.77^{b}$ & $-.30^{b}$ & $-.27^{b}$ \\
\hline Warmth & $.58^{b}$ & $.71^{b}$ & $.76^{b}$ & $.65^{b}$ \\
\hline
\end{tabular}

${ }^{a} P<.01$.

${ }^{b} P<.001$.

The strongest correlations with the quality of care, however, can be found among the global affect-ratings. The positive affects (interest and warmth) show an especially high correlation with all three quality-ratings, as well as with the GP's generalistic orientation.

\section{The Relative Relevance of Different Types of Behavior for the Quality of Care}

To determine the relative influence of the different types of behavior on the three quality ratings, as well as the assessed rate of generalistic orientation, several stepwise multiple regression analyses have been carried out, with the quality ratings successively used as dependent variables and different subsets of behavioral categories and affect-ratings as independent variables. Table 5 gives an overview of the results in terms of a list of the behavioral categories (in order of importance) that have an independent influence on that specific quality measure and the amount of variance that is explained by these variables (in percentages).

The total observation system consists of three main groups of variables: 1) task related behavior, 2) socio-emotional behavior (together forming RIAS), and 3) global affect-ratings. In the upper part of Table 5 , the combined influence of all three main groups on the quality ratings is explained by the observation system as follows:

1. Sixty percent of the variance in the assessment of technical-medical quality is explained by the total observation system, mainly by interest (one of the global affectratings) and giving medical information (belonging to the task-related behaviors). Other task-related behaviors with a small but independent influence on the quality of techni- 
TABLE 5. Summary Stepwise Multiple Regressions with Several Subsets of Doctor-Patient Communication Variables as Independent and Several Quality Measures as Dependent Variable (Percentage Explained Variance (Adjusted $R^{2}$ ); Independent Variables in Order of Relevance)

Quality of Care

\begin{tabular}{|c|c|c|c|c|c|c|c|c|}
\hline & \multicolumn{2}{|c|}{ Medical } & \multicolumn{2}{|c|}{ Psychosocial } & \multicolumn{2}{|c|}{ Doctor-Patient Relationship } & \multicolumn{2}{|c|}{ Generalistic Orientation } \\
\hline & $\begin{array}{l}\% \text { Explained } \\
\text { Variance }\end{array}$ & Variables & $\begin{array}{l}\% \text { Explained } \\
\text { Variance }\end{array}$ & Variables & $\begin{array}{l}\% \text { Explained } \\
\text { Variance }\end{array}$ & Variables & $\begin{array}{l}\% \text { Explained } \\
\text { Variance }\end{array}$ & Variables \\
\hline $\begin{array}{l}\text { I Task-related } \\
\text { behavior + socio- } \\
\text { emotional } \\
\text { behavior affect } \\
\text { ratings }\end{array}$ & 60 & $\begin{array}{l}\text { interest medical } \\
\text { information } \\
\text { psychological } \\
\text { questioning } \\
(-) \text { directions }\end{array}$ & 70 & $\begin{array}{l}\text { interest attentiveness } \\
\text { psychological } \\
\text { information } \\
\text { medical } \\
\text { questioning }(-)\end{array}$ & 59 & $\begin{array}{l}\text { warmth } \\
\text { attentiveness }\end{array}$ & 63 & $\begin{array}{l}\text { interest attentiveness } \\
\text { directions (-) } \\
\text { psychological } \\
\text { information } \\
\text { warmth }\end{array}$ \\
\hline $\begin{array}{l}\text { Ila Socio-emotional } \\
\text { behavior + affect } \\
\text { ratings }\end{array}$ & 51 & $\begin{array}{l}\text { interest } \\
\text { disagree }\end{array}$ & 67 & interest attentiveness & 59 & $\begin{array}{l}\text { warmth } \\
\text { attentiveness }\end{array}$ & 54 & interest attentiveness \\
\hline $\begin{array}{l}\text { IIb Task-related } \\
\text { behavior + socio- } \\
\text { emotional } \\
\text { behavior }\end{array}$ & 24 & $\begin{array}{l}\text { directions } \\
\text { medical } \\
\text { information }\end{array}$ & 30 & $\begin{array}{l}\text { attentiveness } \\
\text { psychological } \\
\text { questioning }\end{array}$ & 25 & $\begin{array}{l}\text { attentiveness social } \\
\text { behavior }\end{array}$ & 46 & $\begin{array}{l}\text { attentiveness social } \\
\text { behavior } \\
\text { psychological } \\
\text { information } \\
\text { medical } \\
\text { counseling (-) } \\
\text { psychological } \\
\text { questioning }\end{array}$ \\
\hline $\begin{array}{l}\text { IIIa Task-related } \\
\text { behavior }\end{array}$ & 24 & $\begin{array}{l}\text { directions } \\
\text { medical } \\
\text { information }\end{array}$ & 21 & $\begin{array}{l}\text { psychological } \\
\text { questions medical } \\
\text { information } \\
\text { psychological } \\
\text { counseling }\end{array}$ & 12 & $\begin{array}{l}\text { medical } \\
\text { information } \\
\text { psychological } \\
\text { questioning }\end{array}$ & 19 & $\begin{array}{l}\text { psychological } \\
\text { questioning } \\
\text { psychological } \\
\text { counseling } \\
\text { medical } \\
\text { information }\end{array}$ \\
\hline $\begin{array}{l}\text { IIIb Socio- } \\
\text { emotional } \\
\text { behavior }\end{array}$ & 16 & $\begin{array}{l}\text { attentiveness } \\
\text { concern }\end{array}$ & 28 & attentiveness & 25 & $\begin{array}{l}\text { attentiveness social } \\
\text { behavior }\end{array}$ & 34 & $\begin{array}{l}\text { attentiveness social } \\
\text { behavior }\end{array}$ \\
\hline IIIc Affect-ratings & 48 & $\begin{array}{l}\text { interest anger } \\
(-)\end{array}$ & 58 & interest & 57 & warmth & 44 & interest warmth \\
\hline
\end{tabular}


cal-medical care are: asking psychosocial questions (this has a negative predictive value) and giving directions or instructions. The socio-emotional behaviors have no independent influence on the quality of medical care.

2. Seventy percent of the variance in the assessment of psychosocial quality can be explained by the total observation system. Here, too, interest (a global affect-rating) has the strongest predictive power, followed by verbal attentiveness (from the socio-emotional behaviors). Task-related behavior also has an independent influence on the assessment of the quality of psychosocial care but only in relation to the topic discussed: the quality of psychosocial care is valued better when the GP gives a lot of psychosocial information and asks few medical questions.

3. Fifty-nine percent of the variance in the assessment of the way the GP manages his or her relationship with the patient is explained by the total observation system. Task-related behavior does not have any influence on this particular quality assessment. It is totally predicted by affective measures, partly from the global affect-ratings (warmth) and partly by the verbal socioemotional behaviors (verbal attentiveness).

4. Sixty-three percent of the variance in GP's generalistic orientation is explained by the observation system, mainly by affective measures (interest, verbal attentiveness and warmth). From the task-related behaviors, giving directions has a small, negative, independent influence, whereas giving psychosocial information has a small, positive influence.

In summary, it can be concluded that the different quality ratings (all being predicted fairly well by the observation system) do show a different communication profile. Global affect seems important in all of them, albeit different types of affect in different quality-ratings. In addition, task-related behavior seems to be more important in technical-medical behavior, whereas socio-emotional behavior, especially verbal attentiveness, seems to be more important in the other quality measures.

The relative relevance of the three main groups can be made visible by the successive removal of one or two of the main groups from the multiple regression analyses. In the second row of Table 5, all task-related behavior is removed from the analysis (row IIa) to demonstrate the influence all affective behavior (verbal socio-emotional behavior, as well as global affect-ratings) on the respective quality measures. Not much explained variance is lost by this operation, ranging from none of the variance in the quality of the GP-patient relationship to $9 \%$ of the variance in the technical- medical quality and the generalistic orientation.

When the global affect-ratings are removed from the multiple regression analyses (row IIb) to demonstrate the influence of the bare RIAS-system, containing all verbal behaviors, the loss of explained variance is more dramatic: RIAS alone explains less than half of the variance that is explained by the total observation system for each of the quality measures: $24 \%$ of technical-medical quality, $30 \%$ of psychosocial quality, and $25 \%$ of the quality of the GP-patient relationship. Only the generalistic orientation is still predicted fairly well by the bare RIASsystem (46\% explained variance). Removal of the global affect-ratings brings one socioemotional behavior whose influence was masked by the overwhelming influence of the global affect-ratings into the open; this is social behavior (which is much like Roter's socio-emotional cluster), which now has an independent influence on the quality of the GP-patient relationship and on GP's generalistic orientation but not on the quality of medical care or the quality or psychosocial care.

In the lower part of Table 5, the relative influence is demonstrated of each of the three main groups (task-related behavior, verbal socio-emotional behavior, and global affect ratings). Moreover, this analysis shows the relative relevance of the different types of behavior within each main group.

Comparing the influence of task-related behavior with verbal socio-emotional behavior (IIIa and IIIb), it is again demonstrated that the task clusters are more important in 
explaining the variance in the medical quality, whereas the socio-emotional clusters are more important in explaining the psychosocial quality, the quality of the GP-patient relationship, and the generalistic orientation. Medical information proves to be the most important task-related behavior: it has an independent influence on all of the quality measures. Of the socio-emotional behaviors, verbal attentiveness is the most important in all types of care. However, of all individual clusters, the global affect-ratings do have the highest predictive power, especially interest and warmth.

\section{Discussion}

The results presented partly corroborate those from the previous studies in which Roter's Interaction Analysis System was used, but they also shed some new light on the controversies found in the literature about the relative relevance of instrumental versus affective behavior. Let us first summarize the major similarities and differences in both studies.

In Roter's study, as well as in ours, the quality of technical-medical care ("proficiency") was better explained by RIAS taskclusters than by RIAS socio-emotional clusters. Also, in Roter's study, as well as in ours, "giving information" and, especially, "giving medical information" proved to be important in the assessed quality of care.

There are, however, also some important differences. First, in our study socio-emotional behavior did correlate substantially with each of the task-related clusters; this was especially true for "verbal attentiveness." This specific component of the GP's socio-emotional behavior also has strong correlations with panel-assessed quality of care and the degree to which the GP shows a generalistic orientation (as opposite to a biomedical orientation). Another major difference in the results of both studies is the importance of the global affect ratings. In our study, these proved to be very important in- deed: in multivariate analyses, the global affect-ratings proved to have the greatest predictive power in all three quality-assessments (the assessment of technical-medical quality, too!), as well as in the panel's rating of the GP's generalistic orientation. Roter's overall conclusion, that task-related behavior (probably because it is in itself affectladen) is more important in medical consultations than affective behavior, cannot be corroborated by the results of this study. On the contrary, just as in our previous publications on the same material, (using another observation system and other observers) affective behavior, especially nonverbal affective behavior, seems to be the most important in determining panel-assessed quality of care ${ }^{31,53}$ An explanation is necessary.

In the last of her two papers about the relative relevance of instrumental or task-related behavior on one hand, and socio-emotional or affective behavior on the other, Roter called on other researchers "to replicate her findings through different methodologies and in the natural setting. ${ }^{\prime 8}$ This call was based on two possible weaknesses of her study: 1) the use of simulated patients instead of real patients, which raises questions about the generalization of the results, and 2) the use of audiotapes instead of videotapes, which limited the possibility to register nonverbal affect to vocal-tone, only. Our study can be seen as such a replication: it took place in the natural setting (real general practitioners with real patients who had hypertension) and used partly different methodologies (video instead of audio, which made it possible to register visual as well vocal cues). In addition, some refinements have been made in RIAS to get a more detailed picture of GP's socio-emotional behavior. It is relevant to consider the differences found in the results of both studies in light of our adaptations in design, methodology, and data analysis.

First, the GP's socio-emotional cluster is considered more closely. Roter found no relationships between the GP's socio-emo- 
tional behavior and his or her task-related behavior, or with several outcome-measures. However, in our study we did find significant relationships between GP's socio-emotional behavior and panel-assessed quality of care. We also found significant relationships between a GP's socio-emotional behavior and his or her task-related behavior. The differences can be explained because, in this study, GP's socio-emotional behavior, while based on exactly the same observation instrument, is considerably different from the original socio-emotional cluster. Roter worked with one socio-emotional cluster, which was based on a factor analysis of all RIAS behavioral categories. She found "no clear socio-emotional factor, although one of the rotated factors did contain substantial loadings for personal remarks and laughs, and loadings for statements of approval and agreement that were higher than the loadings of all but one other content-analysis item on that factor. These four variables were consequently averaged to form a positive socio-emotional cluster. ${ }^{7}$ In this study, three socio-emotional clusters were discriminated on the basis of a factor analysis of the positive socio-emotional behaviors only, each representing a clearly different concept within the socio-emotional domain as follows:

1. "Verbal attentiveness" provides information about the degree the GP is attuned to what the patient volunteers to tell him or her. This factor represents the therapeutic concept of an unconditional positive regard, originally formulated by Rogers, ${ }^{35}$ now considered by most theorists as the nonspecific factor ("factor X") that is the agent in therapeutic processes, regardless of the specific therapeutic school. ${ }^{3,56}$ It is indeed this factor that in this study proved to be responsible for the relationships between socio-emotional behavior and panel-assessed quality. A doctor who shows through verbal behavior that he or she is attuned to what the patient volunteers to tell him or her (by paraphrasing or reflecting what the patient says, showing agreement or partnership, etc.) is considered a "good doctor" in all domains of medical care: technical-medical, psychoso- cial, and in the management of the GP-patient relationship. With the exception of "showing agreement," none of the distinct categories that make up this socio-emotional behavior are used in Roter's concept of socio-emotional behavior.

2. "Showing concern" provides information about the degree to which the GP shows concern about the emotional aspects of patients' health problems by giving reassurance or showing worry. By this behavior the patient can get an idea about the seriousness of his or her health problem. It should guide the patient in labelling himself or herself as ill or healthy, which is important in promoting compliance on the one hand and prevention of somatic fixation on the other. $\mathrm{Al}$ though the relationships are less clear, "showing concern" is also associated with high quality ratings, especially for medical care and the management of the GP-patient relationship.

3. "Social Behavior" provides information about the degree to which the GP indulges in social conversation that has no particular function in the consultation, apart from establishing rapport with the patient. This concept is much like Roter's socio-emotional cluster. ${ }^{7.8}$ It is also much like Wolraich's concept of "social amenities." ${ }^{45}$ As in Roter's study, social behavior did not correlate with the quality of medical care or with GP's task-related behavior. In fact, it proved to be related primarily to the quality of the GP's management of his or her relationship with the patient.

Part of the riddle has been solved: Roter's original socio-emotional cluster is in fact a social cluster. It fits perfectly into Bales' problem-solving theory in which socioemotional behavior is only important as a way to ease the relationship and to facilitate the primary purpose of the conversation: problem-solving. ${ }^{37}$ Medical consultations, however, are more than a problem-solving enterprise. They are also a therapeutic encounter, in which affective behavior is necessary to create a warm and trusting atmosphere; this is a purpose in itself, a secondary purpose, other than the primary purpose of problem-solving. ${ }^{57}$ Our first socio-emotional cluster "verbal attentiveness" (explaining $31 \%$ of the variance in positive so- 
cio-emotional behavior) fits neatly within the psychotherapeutic theories, which claim to provide room for the patient to talk about his or her real worries. ${ }^{53}$ In this study, it is shown to be important in medical consultations, too.

The second major difference (the degree of influence of global affect-ratings on the quality of care) can also be explained by differences in the methodology of both studies. Roter measured global affect by rating the affective quality of electronically filtered voice-tone in selected fragments of the audiotaped consultation. ${ }^{7.8}$ Low correlations were found. In our study, GP's behavior on the total videotaped consultation is rated on global affect-scales, which makes it possible to register visual cues as well as vocal ones (see also Inui et al., 1985). ${ }^{4}$ In this study global affect-ratings proved to be very important indeed. A possible explanation for the differences found is that affective behavior cannot always be heard. Simply looking at the patient has proven to be very important in medical consultations ${ }^{31}$ and even silence can be a very powerful therapeutic weapon, at least when it is used in effectively. With audiotapes, one never can tell if a doctor is looking at his or her records or at the patient. It is also not possible to determine if a joke has an affective role in the consultation by relaxing the patient or if it is meant to end (part) of the consultation, for example when the GP turns his or her head at the same time. Eye aversion is an important technique in controlling the interview. ${ }^{58}$ Mehrabian (cited by Strecher ${ }^{59}$ ) concluded in a broad review of the literature that only $7 \%$ of the emotional communication is transferred via verbal behavior; another $22 \%$ is transferred by voice tone, but only $55 \%$ is transferred by visual cues, eye contact, body positioning, and so on. It is plausible that the better predictive results of our global affect-ratings can be attributed to the use of video instead of audio, at least in part. It is also possible that with real-life patients (our study) affective behavior plays a more important role in the medical consultation than when simulated patients are used, like in Roter's study. This could be due to the fact that in simulations, both GP and patient are primarily attuned to the technical-medical aspects of the consultations and hence show primarily task-related behavior. The simulated patient is trained to present a particular circumscribed somatic problem (in Roter's case: chronic obstructive pulmonary disease); moreover, a simulated patient will not feel the emotions and anxieties of being ill and going to a doctor like a real patient does (paraphrasing Engel, they will primarily feel the need to know and understand and not feel the need to be known and feel understood). ${ }^{32}$

This brings us to the last point we want to discuss: the scope of generalization of the results of our study. It is a study with reallife patients with hypertension who have a long-lasting relationship with the medical system. Unlike the United States, in The Netherlands (which has a health system that is much like the British health system) the patient interacts with the same GP for all of their visits over a long period of time. GP and patient get to know each other fairly well. This makes it possible that communication patterns evolve that are different from communication patterns for more incidental visits. In Zastowny's words: ". . . .some providers may have a care environment into which patients become socialized over time. In some cases the patient-environment fit is a good one from the patient's point of view, whereas in others it is problematic and conflicted, laying seeds for later dissatisfaction." ${ }^{160}$ (p. 720) Listening to the American audiotapes that we used for our training gave us the impression that American doctors have other communication patterns (more detached, more problem-related and task-oriented) than their Dutch colleagues (who seem to show more warmth and pay more attention to the psychosocial aspects of the presented health problems). Whether these differences are caused by working 
with simulated patients versus real-life patients or by cross-cultural differences between general practitioners in different countries can only be determined in a new research project in which real-life consultations of patients with the same health problem from both countries are compared.

\section{Acknowledgments}

We thank Debra Roter for her cooperation and willingness to help us with the application of her observation instrument in our study.

\section{References}

1. Putnam SM, Stiles WB, Casey JM, et al. Patient exposition and physician explanation in initial medical interviews and outcomes of clinic visits. Med Care 1985;23:74.

2. DiMatteo MR. A social-psychological analysis of physician-patient rapport: toward a science of the art of medicine. J Soc Sci 1979;35:12.

3. White K. The Task of Medicine. Menlo Park, CA: The Henry J. Kaiser Family Foundation, 1988.

4. Inui TS, Carter WB. Problems and prospects for health services research on provider-patient communication. Med Care 1985; 23:251.

5. Ben-Sira $Z$. Affective and instrumental components in the physician-patient relationship: an additional dimension of interaction theory. I Health Soc Behav $1980 ; 21: 170$.

6. Fitzpatrick R, Hopkins A. Problems in the conceptual framework of patient satisfaction research: an empirical exploration. Sociology of Health and Illness 1983;5:297.

7. Hall JA, Roter DL, Katz NR. Task versus socioemotional behaviors in physicians. Med Care $1987 ; 25: 399$.

8. Roter DL, Hall JA, Katz NR. Relations between physicians' behaviors and analogue patients' satisfaction, recall and impressions. Med Care 1987; 25:437.

9. Willson P, McNamara JR. How perceptions of a simulated physician-patient interaction influence intended satisfaction and compliance. Soc Sci Med $1982 ; 16: 1699$

10. Ware JE, Snyder MK. Dimensions of patient attitudes regarding doctors and medical care services. Med Care 1975; 13:669.

11. Stoeckle JD. Encounters Between Patients and Doctors: An Anthology. Cambridge, MA: The MIT Press, 1987.

12. Korsch BM, Gozzi EK, Francis V. Gaps in doctorpatient communication I: doctor-patient interaction and satisfaction. Pediatrics 1968;42:855.

13. Svarstad BL. Physician-patient communication and patient conformity with medical advice. In: Me- chanic D. The Growth of Bureaucratic Medicine. New York: John Wiley \& Sons, 1976.

14. Mathews JJ. The communication process in the clinical setting. Soc Sci Med 1983;17:1371.

15. Boreham P, Gibson D. The informative process in private medical consultation: a preliminary investigation. Soc Sci Med 1978; 12:409.

16. Anderson LA, McEvoy DB, Devillis RF. Effects of modeling on patient communication, satisfaction, and knowledge. Med Care 1987; 25:1044.

17. Davis MS. Variation in patients' compliance with doctors' advice: an empirical analysis of patterns of communication. Am J Public Health 1968;58:274.

18. Ley P. Patients' understanding and recall in clinical communication failure In: Pendleton D, Hasler J. Doctor-Patient Communication. London: Academic Press, 1983.

19. Rost K, Roter D. Predictors of recall of medication regimens and recommendations for lifestyle change in elderly patients. Gerontologist 1987;27:510.

20. Heszen-Klemens I, Lapinska E. Doctor-patient interaction, patients' health behavior and effects of treatment. Soc Sci Med 1984; 19:9.

21. Rost K, Carter W, Inui T. Introduction of information during the initial medical visit: consequences for patient follow-through with physician recommendations for medication. Soc Sci Med 1989;28:315.

22. Stewart MA. What is a successful doctor-patient interview? A study of interaction and outcomes. Soc Sci Med 1984; 19:167.

23. Balint M. The Doctor, His Patient and the Illness. London: Pitman Medical Publishing Company, Ltd, 1957.

24. Henderson LJ. Physician and patient as a social system. In: Stoeckle JD. Encounter Between Patient and Doctors: An Anthology. Cambridge, MA: The MIT Press, 1987.

25. Ben-Sira Z. Stress potential and esotericity of health problems: the significance of the physician's affective behavior. Med Care 1982;20:414.

26. Comstock LM, Hooper EM, Goodwin JM, et al. Physician behaviors that correlate with patient satisfaction. J Med Educ 1982;57:105.

27. Feletti GI, Carney SL. Evaluating patient's satisfaction with medical students interviewing skills. J Med Educ 1984; 18:15.

28. Bensing JM, Sluys EM. Evaluation of an interview training course for general practitioners. Soc Sci Med 1985;20:737.

29. Gask I, Goldberg D, Lesser AL, et al. Improving the psychiatric skills of the general practice trainee: an evaluation of a group training course. J Med Educ $1988 ; 22: 132$.

30. Verhaak PFM. Detection of psychological complaints by general practitioners. Med Care 1988;26: 1009.

31. Bensing JM. Doctor-patient communication and the quality of care. Soc Sci Med 1991;32:1301. 
32. Engel GL. How much longer must medicine's science be bound by a seventeenth century world view? In: White K. The Task of Medicine. Menlo Park, CA: The Henry J. Kaiser Family Foundation, 1988.

33. Molleman E, Krabbendam PJ, Annyas AA, et al. The significance of the doctor-patient relationship in coping with cancer. Soc Sci Med 1984;18:475.

34. Bensing JM. Implicit theories in research on doctor-patient communication. In: Bensing JM. Doctor-Patient Communication and the Quality of Care. Rotterdam/Utrecht: The Netherlands Institute for Primary Health Care, 1991. Thesis.

35. Rogers CR. Client-centered-therapy. Boston: Houghton Mifflin, 1951.

36. Klein BM, Buller D. Physicians communication style and patient satisfaction. J Health Soc Behav $1987 ; 28: 375$.

37. Bales RF. Interaction process analysis: a method for the study of small groups. Reading MA: AddisonWesley, 1950.

38. Hall JA, Roter DL, Katz NR. Meta-analysis of correlates of provider behavior in medical encounters. Med Care 1988;26:657.

39. Roter D. The Roter method of interaction process analysis. Baltimore, MD: The Johns Hopkins University, 1989. (unpublished manuscript)

40. Roter DL. Patient participation in the patient provider interaction: the effects of patients question asking on the quality of interaction, satisfaction and compliance. Health Education Monographs 1977; 5:281.

41. Roter DL. Patient question asking in physician patient interaction. Health Psychology 1984;3:395.

42. Hall JA, Roter DL, Rand CS. Communication of affect between patient and physician. J Health Soc Behav $1981 ; 22: 18$.

43. Inui TS, Carter WB, Kukull WA, et al. Outcomebased doctor-patient interaction analysis I: Comparison of techniques. Med Care 1982;20:535.

44. Carter WB, Inui TS, Kukull WA, et al. Outcomebased doctor-patient interaction analysis II. Identifying effective provider and patient behavior. Med Care $1982 ; 20: 550$

45. Wolraich ML, Albanese M, Stone G, et al. Medical communication behavior system: an interaction analysis system for medical interactions. Med Care $1986 ; 24: 891$.

46. Verhaak PFM. Interpretatie en behandeling van psychosociale problemen in de huisartspraktijk; een onderzoek naar verschillen tussen huisartsen. Utrecht/
The Netherlands Institute for Primary Health Care 1986. Thesis.

47. Verhaak PFM. Variations in the diagnosis of psycho-social disorders: a general practice observation study. Soc Sci Med 1986;23:595.

48. Royal College of General Practitioners. Prevention of arterial disease in general practice. Report from general practice. no. 19. London: Royal College of General Practitioners, 1981.

49. Office of Population Censuses and Surveys. Morbidity statistics from general practice. Second national Study 1971-1972. Studies on medical and population subjects, no. 26. London: Her Majesty's Stationary Office, 1979 .

50. Lamberts $H$. Morbidity in general practice: diagnosis-related information from the monitoring project. Utrecht, The Netherlands: Huisartsenpers, 1984.

51. Van der Velden J. Nationale studie van ziekten en verrichtingen in de huisartspraktijk: de rol van de huisartspraktijk in Nederland. Medisch Contact 1990; 45:605.

52. Donabedian A. The definition of quality and approaches to its assessment. In: Explorations in Quality Assessment. Vol. I. Ann Arbor, MI: Health Administration Press, 1980.

53. Bensing JM. Doctor-patient communication and the quality of care: An observation study into affective and instrumental behavior in general practice. Utrecht/ Rotterdam: The Netherlands Institute for Primary Health Care, 1991. Thesis.

54. Dimatter MR, DiNicola DD. Sources of assessment of physician performance: a study of comparative reliability and patterns of intercorrelation. Med Care $1981 ; 19: 829$.

55. Barsky AJ, Kazis LE, Freiden RB. Evaluating the interview in primary care medicine. Soc Sci Med 1980;14a:653.

56. Lemmens F van Busschbach J, de Ridder D, van Lieshout P. Psychotherapie in de RIAGG. Utrecht, NcGv, 1988.

57. Dixon T. Doctors, patients and relationships. Can Fam Phys 1989;35:9.

58. Lovett LM, Cox A, Abou-Saleh M. Teaching psychiatric interview skills to medical students. J Med Educ $1990 ; 24: 243$.

59. Strecher VJ. Improving physician-patient interaction: a review. Patient Counsel Health Educ $1984 ; 4: 129$.

60. Zastowny TR, Roghman KJ, Cafferata GL. Patient satisfaction and the use of health services. Med Care $1989 ; 27 ; 705$. 


\section{Appendix. Observation Form Assessment of Quality.}

No. panel-judge
Tape
Counter
Consultation :

1. Please, express your general opinion of the quality of care:

$\begin{array}{llllllllllll}\text { technical-medical } & 0 & 1 & 2 & 3 & 4 & 5 & 6 & 7 & 8 & 9 & 10 \\ \text { psychological } & 0 & 1 & 2 & 3 & 4 & 5 & 6 & 7 & 8 & 9 & 10 \\ \text { GP-patient relationship } & 0 & 1 & 2 & 3 & 4 & 5 & 6 & 7 & 8 & 9 & 10\end{array}$

2. Please, express your opinion of the general orientation of the GP

Is the GP care-oriented or cure- care

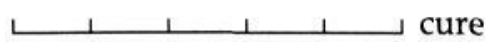
oriented?

Is the GP oriented to the natural sciences or to the behavioral sciences?

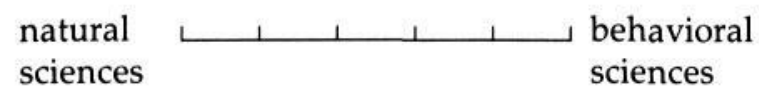

Is the GP's approach businesslike or personal?

businesspersonal like

Is the GP playing safe, or prepared to run risks?

playing safe

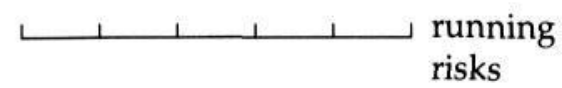

Is the GP patient-centered or disease-centered?

Is the GP's approach biological or psychotherapeutic?

Is the GP maintenance-oriented or intervention-oriented? patientcentered

$\checkmark$ diseasecentered

biological psychotherapeutic

mainintervention

Remarks: 